\title{
A Cidade Média nas Três Fronteiras - Dinâmicas socioespaciais em Foz do Iguaçu (PR)
}

\author{
The Middle-Sized City on the Three Borders - Socio-spatial dynamics in Foz do \\ Iguaçu (PR)
}

\section{La Ciudad Intermedia en las Tres Fronteras - Dinámicas socio-espaciales en Foz do Iguaçu (PR)}

\author{
Alexandre Carvalho de Andrade ${ }^{1}$ \\ https://orcid.org/0000-0002-6787-4285
}

RESUMO: O presente trabalho tem o objetivo de demonstrar as dinâmicas socioespaciais atuais em Foz do Iguaçu (PR), que são decorrentes dos processos de crescimento populacional, expansão urbana e produção do espaço, que incidiram na referida cidade média, no período entre 1970 e 2020. Apesar de recorrentemente ser associada com a monumentalidade de suas paisagens, a magnitude da atividade turística e a diversidade sociocultural de seu cotidiano "de fronteira", Foz do Iguaçu apresenta significativas desigualdades socioespaciais, resultantes de fatores econômicos, políticos e demográficos que incidiram na cidade, mas também na aglomeração urbana das Três Fronteiras.

PALAVRAS-CHAVE: Cidade média. Fronteiras. Dinâmicas socioespaciais. Turismo.

ABSTRACT: This article has the objective to demonstrate current social-spatial dynamics in Foz do Iguaçu (PR), which are arising from processes of population growth, urban expansion and space production that focused in referred middle-sized city, among 1970 and 2020. Despite has been recurrently associate with monumentality of yours landscape, the magnitude of tourist activity and social-cultural diversity in your daily "borderline", Foz do Iguaçu presents significant social-spatial inequality, resulting from economic, political, and demographic factors which focused on the city, but also on urban agglomeration from the Three Borders.

KEYWORDS: Middle-sized city. Borderlines. Social-spatial dynamics. Tourism.

RESUMEN: El presente trabajo tiene el objetivo de demostrar las dinámicas socio-espaciales actuales en Foz do Iguaçu (PR), que son derivadas de los procesos de crecimiento poblacional, expansión urbana y producción del espacio, que incidieron en dicha ciudad intermedia, en el período entre 1970 y 2020. A pesar de ser asociada recurrentemente con la monumentalidad de sus paisajes,

\footnotetext{
1 Doutor em Geografia: Organização do Espaço (2014), na UNESP - Campus de Rio Claro. Professor do Campus Poços de Caldas, do Instituto Federal de Educação, Ciência e Tecnologia do Sul de Minas (IFSULDEMINAS); Professor do Programa de Pós-Graduação em Geografia da Universidade Federal de Alfenas (UNIFAL-MG). E-mail: alexandre.andrade@ifsuldeminas.edu.br.
} 
la magnitud de la actividad turística y la diversidad sociocultural de su cotidiano "de frontera", Foz do Iguaçu presenta significativas desigualdades socio-espaciales, resultantes de factores económicos, políticos y demográficos que se centraron en la ciudad, si no también en la aglomeración urbana de las Tres Fronteras.

PALABRAS-CLAVE: Ciudad media. Fronteras. Dinámicas socio-espaciales. Turismo.

\section{INTRODUÇÃO}

Por seu contingente demográfico, importância na rede urbana regional e por suas condições socioespaciais, Foz do Iguaçu é considerada como uma cidade média. No REGIC (IBGE, 2018), por exemplo, o município é classificado como uma "Capital Regional C", estando assim em uma posição intermediária na rede, pois ao mesmo tempo em que polariza cidades do oeste paranaense é polarizada por Curitiba. Além disso, por se encontrar na mais populosa "Aglomeração Urbana Internacional" que envolve um município brasileiro, Foz do Iguaçu mantém, historicamente, relações econômicas e socioculturais bastante intensas com suas vizinhas Puerto Iguazu (Argentina) e Gran Ciudad del Este, composta por: Ciudad del Este, Hernandarias, Los Cedrales, Minga Guazú e Presidente Franco (Paraguai).

Conhecida internacionalmente por seus atrativos turísticos, sendo que os principais deles são compartilhados com os países vizinhos, como as Cataratas do Iguaçu (Brasil e Argentina) e a Usina Hidrelétrica de Itaipu Binacional (Brasil e Paraguai), Foz do Iguaçu apresentou um processo de rápido crescimento populacional e, por consequência, de expansão urbana, em especial após o início dos anos 1970. E isto também aconteceu por fatores econômicos, políticos e socioespaciais que muitas vezes se inter-relacionam com os das localidades transfronteiriças. E, em uma região conhecida pela monumentalidade de suas paisagens e pelos cotidianos entre pontes e fronteiras, diversos problemas se reproduzem em termos socioeconômicos, ambientais e de organização espacial.

Este artigo tem como objetivo demonstrar os processos demográficos, econômicos, e de expansão do espaço urbano que ocorreram na cidade de Foz do Iguaçu, entre os anos 1970 e 2020, e como estes colaboraram para as condições socioespaciais da cidade na atualidade. Para tanto, foram utilizados procedimentos metodológicos como levantamento bibliográfico, cartográfico e de documentos oficiais, análise de dados secundários e de estudos sobre a rede urbana, e trabalhos de campo com registros fotográficos, nos mais diversos setores da Aglomeração Urbana das Três Fronteiras, com ênfase na cidade de Foz do Iguaçu, onde foram contempladas áreas como o centro e as distintas periferias, mas, 
também, as dinâmicas de uso e ocupação do solo em suas áreas de fronteiras (pontes e subcentros), assim como dos espaços turísticos (atrativos, estrutura e disposição espacial).

O "urbano" pode ser analisado por meio de três linhas de investigação: o processo de urbanização; a cidade na escala de uma rede urbana; e o espaço intraurbano (CORRÊA, 2003). Serão levados em conta, portanto, estes pressupostos do autor na estruturação do presente artigo. Assim, nas próximas seções são evidenciados os processos de crescimento populacional e de expansão urbana, para, em seguida, demonstrar a situação de Foz do Iguaçu em suas redes urbanas, para, posteriormente, serem elucidadas questões socioespaciais que coexistem e se sucedem em uma cidade média brasileira de fronteira.

\section{CRESCIMENTO POPULACIONAL NAS "TRÊS FRONTEIRAS”}

A década de 1970 é associada com um momento no qual as cidades médias brasileiras, gradativamente, passam a apresentar contínuo processo de crescimento populacional e de modernização de suas bases econômicas e socioculturais, passando a constituir locais com relevantes contribuições para o desenvolvimento das redes urbanas em que se encontram inseridas (SPOSITO, 2006; CORRÊA, 2007; CONTE, 2013; BATELLA, 2019). Mas, ao mesmo tempo em que se reproduzem aspectos positivos, alguns impactos socioambientais também passaram a incidir nas cidades médias, resultados das ineficiências das políticas públicas e das desigualdades socioeconômicas de seus moradores e investidores.

No contexto de Foz do Iguaçu, a implantação da Usina Hidrelétrica de Itaipu Binacional, em conjunto com o Paraguai, desde meados da década de 1970, favoreceu a intensa modificação de suas dinâmicas demográficas, econômicas e socioculturais, o que faz com que a história da cidade possa ser dividida entre o "antes e o depois" da referida usina (ROSEIRA, 2006; RIBEIRO, 2006; ANDRADE, 2019; DRUCIAKI, 2019). No período entre os inícios das décadas de 1970 e 2010 houve um intenso crescimento populacional em Foz do Iguaçu e na Aglomeração Urbana das Três Fronteiras (tabela 1).

Tabela 1 - Crescimento populacional na Aglomeração Urbana das Três Fronteiras, entre o início da década de 1970 e 2010

\begin{tabular}{lccc}
\hline & Início dos anos 1970 & Início dos anos 1990 & 2010 \\
\hline Foz do Iguaçu & 33.870 & 190.123 & 256.088 \\
Gran Ciudad del Este & 59.329 & 247.897 & 503.618 \\
Puerto Iguazu & 3.001 & 28.083 & 82.849 \\
Três Fronteiras & 96.200 & 466.103 & 842.555 \\
\hline
\end{tabular}

Fonte: Foz do Iguaçu (IBGE, 1970; 1991; 2010); Gran Ciudad del Este (DGEEC, 1972; 1992; 2012); Puerto Iguazú (INDEC, 1970; 1990; 2010). 
A Aglomeração Urbana das Três Fronteiras, apesar de possuir diversas similaridades geográficas, e ter uma intensa relação econômica e sociocultural entre seus moradores, apresenta diferentes papeis de suas cidades, em seus respectivos países, em termos demográficos, econômicos, políticos e estratégicos.

Puerto Iguazú, apesar de ter apresentado significativo crescimento demográfico após 1970, é a menos populosa da aglomeração, está situada em uma das menos desenvolvidas províncias argentinas (Missiones), e tem pequena relevância econômica e demográfica no conjunto do país; apesar disso, conta com ligações aéreas e rodoviárias com diferentes regiões da Argentina e com países vizinhos (DRUCIAKI, 2019). Em 1985 foi inaugurada a ponte da Fraternidade, entre Argentina e Brasil, antes dependente, nesta área, das travessias de balsas. Isso favoreceu a maior inter-relação entre os países, e também incrementou o turismo e o comércio local. É fundamental mencionar, também, que a montante da ponte estão as Cataratas do Iguaçu, na fronteira entre os dois países, que constitui um dos principais e mais visitados atrativos turísticos da América do Sul (CURY e FRAGA, 2013).

Foz do Iguaçu, pelo seu contingente populacional, sua economia e papel na rede urbana, é considerada como uma cidade média de importância regional dentro do Brasil. Por sua vez, localizada no país menos populoso e de menor desenvolvimento econômico das Três Fronteiras, a Gran Ciudad del Este constitui uma das principais regiões econômicas paraguaias, juntamente com Assunção, e possui papel importante na demografia $(8,5 \%$ da população nacional) e foi foco de diversas políticas públicas estratégicas do país (CARDIN, 2010). Juntas, Foz do Iguaçu e a Gran Ciudad del Este possuem mais de $90 \%$ da população da Aglomeração Urbana das Três Fronteiras (Tabela 1), e a circulação de pessoas, veículos e mercadorias entre elas é intensa. Na figura 1 é mostrado o contexto urbano regional.

"A fronteira não é uma linha, a fronteira é um dos elementos da comunicação biossocial que assume uma função reguladora. Ela é a expressão de um equilíbrio dinâmico que não se encontra somente no sistema territorial, mas em todos os sistemas biossociais" (RAFESTIN, 2005, p. 13). As relações entre Foz do Iguaçu e as cidades fronteiriças, em especial as paraguaias, apresentaram diversas mudanças e ressignificações a partir dos anos 1960, em especial devido à inauguração da Ponte da Amizade (1965), e as obras da construção da Usina Hidrelétrica Itaipu Binacional, nos anos 1970 e 1980.

Em seu apogeu, entre os anos de 1978 e 1981, as obras das construções da represa e da barragem da Usina Hidrelétrica de Itaipu Binacional chegaram a empregar mais de 30 mil trabalhadores, sendo, destes, aproximadamente 20 mil brasileiros e os demais paraguaios (CATTA, 2003). As obras chegam ao fim em outubro de 1982, e em 1984 começou o fornecimento de energia da primeira unidade geradora; as demais foram sendo 
implantadas até o ano de 1991, sendo que a capacidade máxima da usina foi atingida apenas no ano de 2007 (ITAIPU BINACIONAL, 2019). O encerramento das obras que demandavam maior mão de obra levou a intensiva demissão de funcionários, e esta situação agravou as condições de emprego. Neste contexto, o turismo, e especialmente o comércio no Paraguai, passaram a ser importantes oportunidades de rendimentos para os moradores de Foz do Iguaçu, assim como da Gran Ciudad del Este (RABOSSI, 2004; CARDIN, 2006; 2010).

Figura 1 - Aglomeração Urbanas das Três Fronteiras

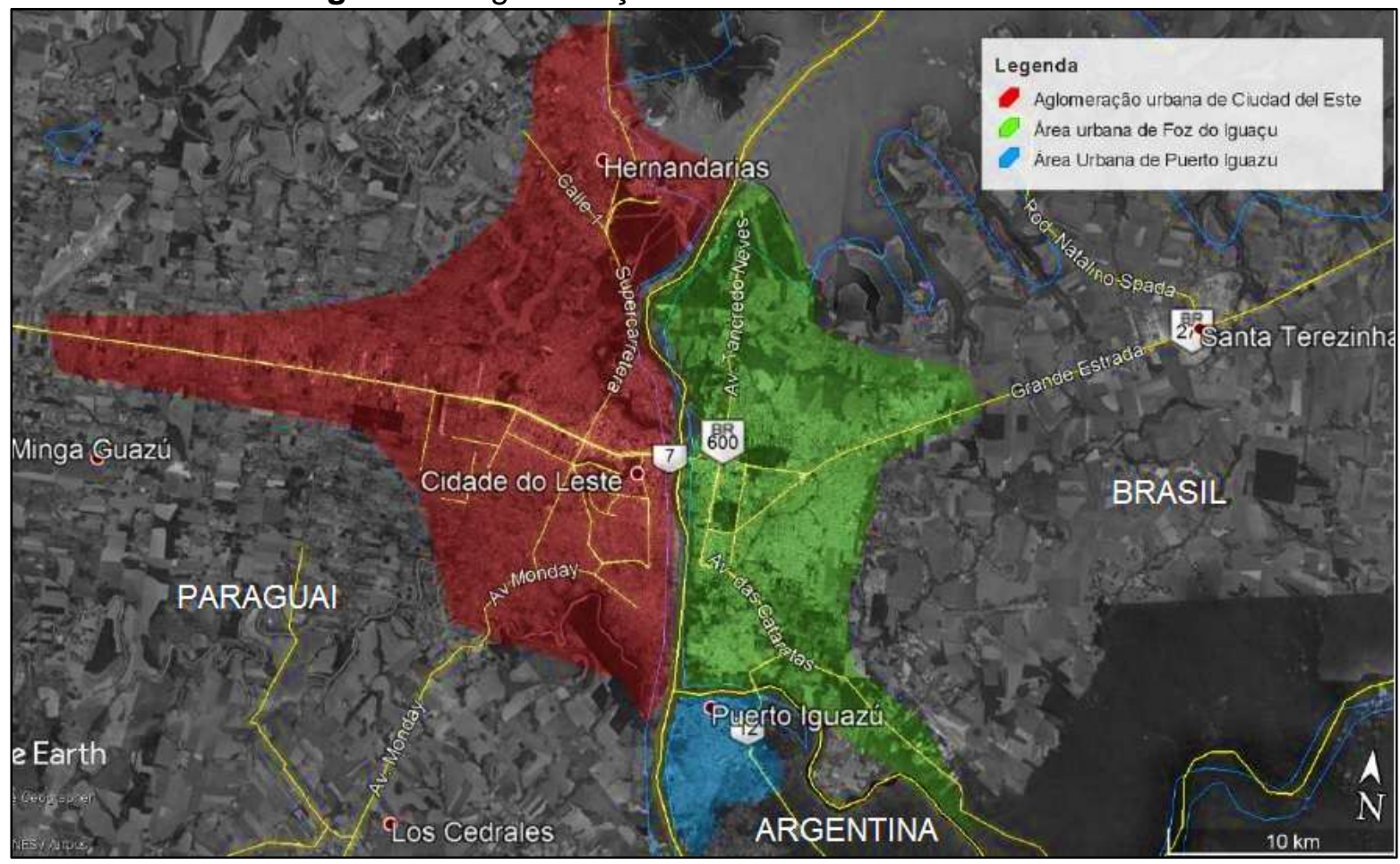

Fonte: Druciaki, 2019.

As populações de ambos os lados da fronteira tiveram significativo crescimento, a partir de 1970, e a afluência de migrantes teve papel fundamental. Rabossi (2004) constatou que Ciudad del Este e as cidades vizinhas atraíram significativos contingentes de migrantes, provenientes dos mais diversos departamentos paraguaios, que objetivavam obter empregos junto a Itaipu, sendo que, na medida em que estes não obtinham trabalhos na usina e/ou eram demitidos, o comércio de importados de Ciudad del Este muitas vezes era visto como lócus de possibilidades econômicas, e em diversos casos era mais rentável que a própria Itaipu.

Um número significativo de brasileiros, proveniente das mais diversas regiões, também se deslocou para a área, seja para Foz do Iguaçu, no intuito de trabalhar em Itaipu (RIPPEL, 2005), e em outras atividades econômicas, como turismo, comércio e serviços, ou em direção ao Paraguai, os denominados "brasiguaios", motivados por políticas de atração 
do governo deste país, mas também pelo menor custo da terra para a produção agropecuária e a proximidade geográfica com o Brasil (ROSEIRA, 2006), e a maior parte destes se fixou no departamento de Alto Paraná, do qual Ciudad del Este é a capital (CURY,2010). Por fim, houve uma significativa imigração de árabes (especialmente libaneses e palestinos), chineses (principalmente de Taiwan), coreanos, indianos e pessoas de outras nacionalidades, que foram atraídas pelo comércio de importados no Paraguai (RABOSSI, 2004), e muitos destes residem na cidade de Foz do Iguaçu, e desenvolvem migrações pendulares para o trabalho em Ciudad del Este.

\section{DINÂMICAS SOCIOECONÔMICAS, EXPANSÃO URBANA E OCUPAÇÃO DO ESPAÇO EM UMA CIDADE MÉDIA DE FRONTEIRA}

Foz do Iguaçu progressivamente foi apresentando maior população e diversificação econômica e sociocultural, o que a fez se consolidar como uma cidade média. Com isso, novas práticas econômicas, ações políticas e dinâmicas socioespaciais, nas escalas intraurbana e da Aglomeração Urbana das Três Fronteiras, foram se articulando, e se refletiram na expansão urbana (figura 2).

O crescimento populacional, as ações políticas, que incluem Itaipu, e as dinâmicas econômicas locais e regionais colaboraram para a expansão urbana de Foz do Iguaçu e para a fragmentação do espaço de acordo com os interesses políticos e as condições socioeconômicas de seus moradores e investidores.

Segundo Taumaturgo (2011), três fatores favoreceram novas dinâmicas econômicas em Foz do Iguaçu a partir dos anos 1970: Itaipu, com o expressivo número de empregados durante a obra, para seu funcionamento após o fim da construção, mesmo que em menor número; o turismo, tanto o "de lazer" voltado às Cataratas, quanto o turismo "de compras" em Ciudad del Este; e o comércio internacional, em especial com o Paraguai. Acrescenta a isto as estruturas comerciais e de prestação de serviços "típicos de uma cidade média", que atendem aos moradores locais e de sua área de influência, como instituições de ensino superior, hospitais, e shopping-centers, dentre outros (ANDRADE, 2019).

Cada uma a sua maneira e a seu tempo, estas práticas econômicas se apropriaram diferentemente dos espaços da cidade de Foz do Iguaçu, e produziram variados usos e práticas. No ano de 1975, elucidado no mapa da figura 2, a área urbanizada era um tanto reduzida, e era composta pela área central, alguns bairros adjacentes, e já apareciam algumas áreas favelizadas (no mapa colocado como "invasões"); era um período em que se iniciavam as construções da Usina Hidrelétrica de Itaipu Binacional. 
Figura 2 - Expansão urbana em Foz do Iguaçu, no período entre 1975 e 2007

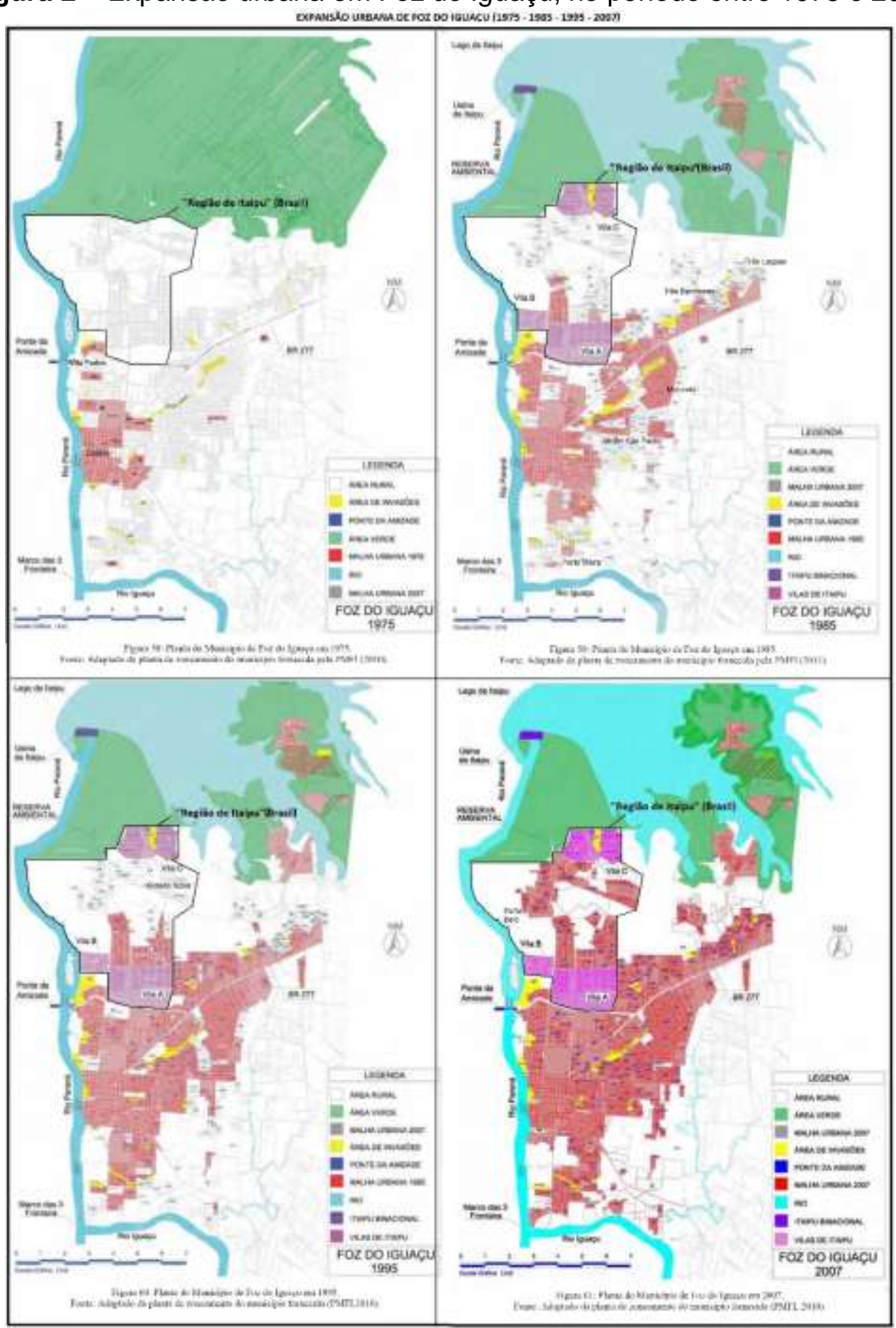

Fonte: Thaumaturgo (2011). Modificado pelo autor.

Quanto ao território municipal, no espaço de tempo entre 1975 e 1985 duas situações resultaram na redução de sua extensão: o reservatório de Itaipu, que alagou amplas áreas (a norte), e a emancipação do município de Santa Terezinha do Itaipu (a leste). Com um território margeado por rios e fronteiras internacionais a oeste e a sul, e tendo parte do Parque Nacional do Iguaçu (sudeste), houve a diminuição dos espaços até então rurais e geralmente voltados às práticas agropecuárias, que foram progressivamente sendo urbanizados. Entretanto, ao mesmo tempo em que houve uma redução do território 
municipal, ocorreu um significativo crescimento populacional, em sua maior parte decorrente da migração (RIPPEL, 2005), e isto refletiu na expansão urbana na década entre 1975 e 1985; neste período se inicia a ocupação das áreas entre o centro e a "região de Itaipu", e nesta última já há a presença das três Vilas de Itaipu, voltadas aos trabalhadores envolvidos na construção da usina.

Devido à necessidade de alocar seus funcionários, e tendo em vista a pequena infraestrutura e oferta de moradias existentes na cidade de Foz do Iguaçu, assim como nas vizinhas paraguaias, a Itaipu Binacional realizou um plano de intervenções que chamou de "Planejamento Global Brasil/Paraguai", e, dentre outras coisas, implantou, por meio de empresas privadas organizadas em um consórcio, vias de acessos, parques, escolas, equipamentos comunitários, hospitais e postos de saúde, além de 11 conjuntos habitacionais, sendo oito no Paraguai e três no Brasil (ANDRADE, 2019). No total foram construídas 9.480 unidades residenciais, destas 5.199 em território brasileiro (SOUZA, 2011), e também alojamentos no canteiro de obras para funcionários solteiros (RIBEIRO, 2006). Quando receberam seus primeiros moradores, as vilas de Itaipu estavam geograficamente um tanto quanto isoladas do centro e do restante da cidade, o que evidencia um processo de fragmentação do espaço urbano de Foz do Iguaçu, e que foi induzido pelas ações dos agentes envolvidos na implantação da usina.

Os moradores das três vilas de Itaipu, apesar das diferenças entre rendimentos e apropriações do espaço entre seus funcionários (Vila A - técnicos, Vila B - profissionais com nível superior, e Vila $C$ - trabalhadores "braçais), tinham melhores salários e condições de vida mais satisfatórias do que na média da cidade (RIBEIRO, 2003). Iguaçuenses e migrantes nacionais de maior poder aquisitivo, acrescidos por imigrantes internacionais envolvidos em sua maior parte com o comércio no Paraguai, passaram a adquirir imóveis, para morar e/ou investir, na área central e adjacências, e colaboraram efetivamente para aumentar a especulação imobiliária que impactou toda a cidade (MAZZAROLLO, 2003; SOUZA, 2009). Aos mais pobres, neste momento (1975-1985), restou optar pelos loteamentos que urbanizavam áreas rurais, tais como Rincão São Francisco (atual bairro do Morumbi e adjacências), Jardim São Paulo, Porto Meira e Três Lagoas, distantes da área central e da "região de Itaipu", e houve também um intensivo processo de favelização, no entorno do centro da cidade, nas barrancas do rio Paraná, e nas periferias (CATTA, 1994; SOUZA, 1998; MAZZAROLLO, 2003; SOUZA, 2009).

Entre os anos de 1974 e 1982 foram implantados 79 novos loteamentos, especialmente em áreas periféricas, como Porto Meira (ao sul da área central), Jardim São Paulo (leste), "região do Rincão do São Francisco" e Três Lagoas (a nordeste), que, por vezes, apresentavam evidentes precariedades socioambientais (SOUZA, 2009). A 
comercialização de imóveis nestas áreas, inclusive em um mercado informal e sem títulos legais de propriedade, foi prática recorrente entre as décadas de 1970 e 1990, assim como foram as ameaças de despejos e, por consequência, as ações de resistências dos moradores e a formação de organizações sociais (GASPAR, 2017).

O fim das obras de construção da barragem e da represa da Usina Hidrelétrica de Itaipu Binacional, como anteriormente mencionado, se deu no início dos anos 1980. Isto agravou as condições de emprego e renda na cidade de Foz do Iguaçu, e também na Gran Ciudad del Este. E, tendo em vista que esta foi uma época em que houve intensa chegada de migrantes para ambos os lados da fronteira, outras práticas econômicas passaram a ser desenvolvidas, dentre elas o turismo e o comércio no Paraguai. Porém, sem condições de absorver a totalidade da mão de obra dispensada pela usina, e pela chegada de novos moradores, passaram a ser comuns os diversos tipos de subempregos e informalidades e, com a piora dos rendimentos e mesmo de empregos regulares, aliados á falta de políticas habitacionais, houve um aumento no número de moradias e habitantes em amplas áreas favelizadas, assim como se agravaram problemas de infraestrutura urbana, criminalidade, tráfico e contrabando.

Entre 1985 e 1995, de acordo com os mapas da figura 2, proporcionalmente a expansão urbana foi menos acentuada do que no período anterior (1975-1985). Todavia houve um maior adensamento e a efetiva ocupação das áreas anteriormente loteadas, e um aumento da verticalização, neste caso sobretudo na área central da cidade de Foz do Iguaçu.

Entretanto, também neste período foi que houve o maior número de abertura de estabelecimentos de hospedagem no município de Foz do Iguaçu (SOUZA, 2009; RIBEIRO, 2015). E estas estruturas visavam atender ao turismo de negócios, típicos de uma cidade média, mas também aos turistas "de lazer" e aos turistas "de compras". Os "turistas de lazer" são os que visitam a cidade e a região no intuito recreativo, e em sua maior parte ficam nos hotéis do centro e da rodovia das Cataratas e suas imediações, geralmente hospedarias de grande porte, pertencentes a redes nacionais ou internacionais do setor (SOUZA, 2009); os "turistas de compras" são compostos pelos "sacoleiros", provenientes das mais diversas regiões do Brasil, com o intuito de realizar compras em Ciudad del Este e, quando se hospedam, são em pequenos hotéis localizados próximos à Ponte da Amizade e nas vias em direção ao centro e ao terminal rodoviário (RABOSSI, 2004; CARDIN, 2006; 2010). Porém, apesar das diferenças, ambas as situações favoreceram a expansão e o adensamento da área urbanizada, entre 1985 e 1995, sendo ao sul e a sudeste com importante colaboração das estruturas turísticas voltadas aos "turistas de lazer", e as áreas em direção a Ponte da Amizade, nas periferias empobrecidas, e na "região de Itaipu" 
(expansão de bairros contíguos a "Vila A"), um tanto influenciadas pelas oportunidades atreladas ao "turismo de compras".

No comércio de Ciudad del Este, no período até meados dos anos 1980, havia a prevalência, de acordo com o termo utilizado por Rabossi (2004), dos "turistas-turistas" (que vão para a região "passear", diferente do "turista-comprista", que visitam para trabalho), e os estabelecimentos comerciais funcionavam especialmente no período noturno, muitas vezes visitados por brasileiros que também iam ao Cassino/Hotel Acaray, fundado em 1969; no início se vendiam produtos "típicos paraguaios" (artesanatos, gastronomia) e predominavam os produtos importados de maior qualidade e "inovadores", ou seja, que não eram encontrados no Brasil ou na Argentina. Posteriormente, no fim dos anos 1980 e início dos anos 1990, com a expansão e a consolidação do turismo de compras, o horário de funcionamento das lojas se alterou para os períodos matutino e vespertino, e as falsificações e produtos de "segunda linha" ganharam grande impulso, e passaram a disputar com os produtos originais o interesse dos consumidores. Atualmente, apenas alguns shoppings de maior porte, que agregam atividades comerciais, praças de alimentação e serviços de entretenimento, funcionam até o período noturno no microcentro de Ciudad del Este.

A segunda metade da década de 1980 até os últimos anos da década de 1990 foi o período no qual o "turismo de compras" teve maior dinamismo e envolveu maior montante de recursos financeiros e de trabalhadores, sendo, segundo Rabossi (2004), os anos de 1994 e 1995, com movimentos superiores a 60 mil "turistas de compra" por semana, os de maior fluxo neste período. De acordo com uma pesquisa do Banco Central do Paraguai, de 1998, 28\% dos estabelecimentos comerciais de Ciudad del Este eram de paraguaios, 27\% de orientais (principalmente taiwaneses), $24 \%$ de árabes (especialmente libaneses e palestinos), $11 \%$ de brasileiros e $10 \%$ não especificados; neste momento os estabelecimentos comerciais chegaram a 7.000, e haviam ainda os "comerciantes de rua", sejam eles os ambulantes, mesiteros, cajeros e casilleros que eram milhares, em sua maior parte paraguaios (RABOSSI, 2004). Alguns destes imigrantes, em especial os árabes e os taiwaneses, eram proprietários de grandes lojas, como Casa China, Biblos e Monalisa, dentre outras, que comercializavam uma significativa diversidade de produtos (eletrônicos, relógios, artigos esportivos...), de marcas mundialmente conhecidas.

Por sua vez, além dos turistas de compras, recorrentemente associados como sacoleiros, provenientes das mais diversas partes do Brasil, existem, envolvidos com as atividades comerciais de Ciudad del Este, diversas pessoas de Foz do Iguaçu, que transitam entre a formalidade e a informalidade, em práticas como laranjas,' taxistas, proprietários de estabelecimentos comerciais, mototaxistas, balconistas e hoteleiros, dentre outras. Famílias 
inteiras de moradores da cidade dependiam (e ainda dependem) da cadeia produtiva atrelada ao comércio no Paraguai, sendo que, em pesquisas realizadas pela Prefeitura Municipal, no início dos anos 2000 foram constatadas que $56 \%$ das pessoas "em idade ativa" do município trabalharam ou trabalhavam em atividades ligadas ao comércio de Ciudad del Este (CARDIN, 2006; 2010). No comércio paraguaio, a maior parte dos empregados em lojas também era composta por brasileiros, que somavam aproximadamente 15.000 trabalhadores em meados dos anos 1990 , o que equivalia a $65 \%$ do total (RABOSSI, 2004). Esta população, em sua maioria residente em bairros periféricos de Foz do Iguaçu ou nas proximidades da Ponte da Amizade, realizava, e realiza, migração pendular diária ao Paraguai, por variadas formas de ir e vir, tais como transporte público, veículos particulares, vans, ou atravessando a pé a ponte.

O comércio do Paraguai, e as diversas atividades a ele relacionadas, apresentou, e ainda apresenta, mesmo que em menor intensidade, significativa importância para a geração de emprego e renda aos moradores de Foz do Iguaçu. Entretanto, fatores resultantes de ordens e conjunturas externas ao território municipal, como a maior intensificação da fiscalização nas fronteiras, a maior pressão dos comerciantes, da mídia e dos órgãos públicos brasileiros pelo fim do "contrabando" proveniente do Paraguai, as oscilações cambiais, e mesmo a concorrência com outros mercados (inclusive os virtuais) que abastecem os lojistas e consumidores brasileiros, contribuíram para que as atividades de compras no Paraguai sofressem significativa queda a partir do final dos anos $1990 \mathrm{e}$ início dos anos 2000 (RABOSSI, 2004; ROSEIRA, 2006; CARDIN, 2006; 2010; ANDRADE, 2019). E, devido a sua importância para a economia formal e informal de Foz do Iguaçu, houve um aumento do desemprego, da informalidade, da pobreza, e da emigração para outras regiões do Paraná e do Brasil.

Nas áreas próximas à Ponte da Amizade, era (e ainda é) perceptível o predomínio de uma paisagem degradada, o acúmulo de poluição (sonora, atmosférica e visual), a sensação de abandono/improviso das edificações, e de "descontrole" atrelado ao trânsito caótico. Importante mencionar que, se por um lado era intenso o fluxo de brasileiros que buscavam produtos no comércio de Ciudad del Este, na região próxima à Ponte da Amizade e nos bairros de Vila Portes e do Jardim Jupira se desenvolveram atividades comerciais, atacadistas e varejistas, voltadas à população paraguaia, que buscava (e busca) nesta área por produtos alimentícios, materiais de construção, têxteis e calçados, dentre outros. Esta região, ao norte da BR-277 (Jardim Jupira), passou a ser popularmente chamada de "Exportação", onde predominava o comércio atacadista, e entrou em declínio, a partir de meados dos anos 1990, devido a fatores externos ao lugar, como a criação do Mercosul, concorrência com outros mercados, oscilação nas cotações das moedas nacionais etc. 
(CARDIN, 2006, 2010), mas também foi prejudicada devido à duplicação da rodovia, que desfavoreceu sua transposição por veículos e pessoas, "isolando" a área.

No período entre 1995 e 2007, a expansão da área urbana foi a menor dentre os períodos analisados (mapas da figura 2). Foz do Iguaçu teve um pequeno declínio em seu contingente populacional, de 258.543 habitantes para 256.088, entre 2000 e 2010 (IBGE, $2000,2010)$. Isto é resultado da redução das taxas de natalidade, algo que ocorreu em todo o território brasileiro, mas especialmente do saldo migratório negativo, que já ocorria no final dos anos 1990 (RIPPEL, 2005).

Apesar da estagnação demográfica ocorrida em Foz do Iguaçu nas últimas décadas, os processos históricos de produção do espaço, em especial no último quarto do século XX, resultaram no crescimento rápido, desordenado e socioeconomicamente desigual nas cidades da Aglomeração Urbana das Três Fronteiras, entre elas Foz do Iguaçu.

A produção do espaço urbano de Foz do Iguaçu, foi marcada, portanto, por uma dualidade nos investimentos públicos, fazendo haver a "cidade para o turista", sinalizada, pavimentada, limpa, arborizada e acessível, e a "cidade vivida pelos moradores pobres", marcada pelas diversas precariedades de serviços públicos, e áreas com paisagens e qualidade socioambientais deterioradas (SOUZA, 2009). Este contraste, entre as áreas turísticas e as áreas empobrecidas, ocorre em diversas cidades médias e metrópoles brasileiras, que apresentam importante funções turísticas (SERPA, 2002; YÁZIGI, 2003). Mas, no contexto de Foz do Iguaçu, é fundamental mencionar que estes melhoramentos urbanos em "áreas turísticas" ocorreram com maior intensidade no centro e deste em direção às Cataratas do Iguaçu, mas não nas áreas das proximidades da Ponte da Amizade, onde transita a maioria dos sacoleiros e trabalhadores ligados ao "turismo de compra".

\section{FOZ DO IGUAÇU, UMA CIDADE MÉDIA E SUA REDE URBANA TRANSFRONTEIRIÇA}

Foz do Iguaçu, em 1966, era considerada como um "centro local", e em 1978 como um "centro de zona", sendo estas as menores categorias dentre as cidades que apresentavam alguma polarização no território regional e nacional. Porém, com as dinâmicas econômicas e demográficas ocorridas, em 2007 a cidade passou a ser considerada como um "centro subregional A", estando polarizada por Cascavel (Capital Regional B) e Curitiba (Metrópole), mas ao mesmo tempo polarizando municípios do extremo oeste paranaense, dentre eles Itaipulândia, Medianeira, Santa Terezinha do Itaipu e São Miguel do Iguaçu (IBGE, 2008). Em 2018, pelo mesmo estudo, a Aglomeração Internacional Foz do Iguaçu-Ciudad del Este é considerada como "Capital Regional C" (IBGE, 2018). Os moradores de sua área de influência recorrentemente se dirigem à Foz do Iguaçu para atividades como compras, 
obtenção de serviços de saúde, realizar cursos superiores, trabalhar e entretenimento, dentre outras.

Além de seu papel de cidade média na rede urbana brasileira, analisada nos estudos do REGIC, é de se levar em conta as importantes inter-relações na Aglomeração Urbana das Três Fronteiras. Há um "continuum urbano" nesta região, em decorrência dos constantes deslocamentos de pessoas por entre as fronteiras dos países, por razões econômicas e socioculturais (RABOSSI, 2004).

O movimento diário é intenso entre as fronteiras, sendo que, segundo dados de junho de 2017, passaram 28.714 pessoas e 8.563 veículos na Ponte da Fraternidade (BrasilArgentina), e 113.907 pessoas e 38.907 veículos na Ponte da Amizade (PREFEITURA MUNICIPAL DE FOZ DO IGUAÇU, 2017).

A circulação entre Foz do Iguaçu e Puerto Iguazú é, em sua maioria, motivada pelas atividades de turismo e recreação e, em menor escala, para o comércio. Há fatores de atração no território argentino, tais como as Cataratas do Iguaçu, Free-Shop, Cassino, comércio e restaurantes de comidas típicas, dentre outros, o que faz que seja bastante recorrente que turistas hospedados no Brasil visitem a Argentina e vice-versa, e o mesmo acontece com as populações das cidades fronteiriças (CONTE, 2013). Porém, por ser mais populosa e desenvolvida economicamente, Foz do Iguaçu atrai moradores de Puerto Iguazú, por motivações atreladas ao comércio, serviços e entretenimento.

Enquanto isso, no intercâmbio entre o Brasil e o Paraguai há uma maior complexidade, intensidade e diversidade nos deslocamentos, sendo especialmente voltados ao trabalho (migração pendular e turismo de compras), acesso aos serviços de saúde, estudos e entretenimento. A influência de Foz de Iguaçu inclusive ultrapassa a Gran Ciudad del Este e atinge outras municipalidades do Departamento de Alto Paraná, seja por intermédio de empresas localizadas no Brasil que atuam em território paraguaio, ou por fornecer serviços médicos e educacionais; e muito disso se dá em decorrência dos "brasiguaios" que entre imigrantes e seus descendentes somam aproximadamente 250 mil pessoas (CURY, 2010). Foz do Iguaçu, de acordo com Roseira (2006, p. 32) é, portanto, "[...] centralizadora e irradiadora de um conjunto de atividades que a caracteriza como importante polo de uma região transfronteiriça".

\section{DINÂMICAS SOCIOESPACIAIS RECENTES NA CIDADE DE FOZ DO IGUAÇU}

A partir dos anos 1990 e especialmente da primeira década do presente século, a produção do espaço urbano de Foz do Iguaçu passa a apresentar novas dinâmicas socioespaciais, devido às suas condições como centro receptor de turistas e de cidade média com significativa polarização na rede urbana regional. $E$ isto se reflete não só nas 
áreas de expansão, mas também nos tipos de usos dos solos, e na constituição de novas centralidades no espaço urbano local (Figura 3).

Figura 3 - Equipamentos urbanos na cidade de Foz do Iguaçu (2019)

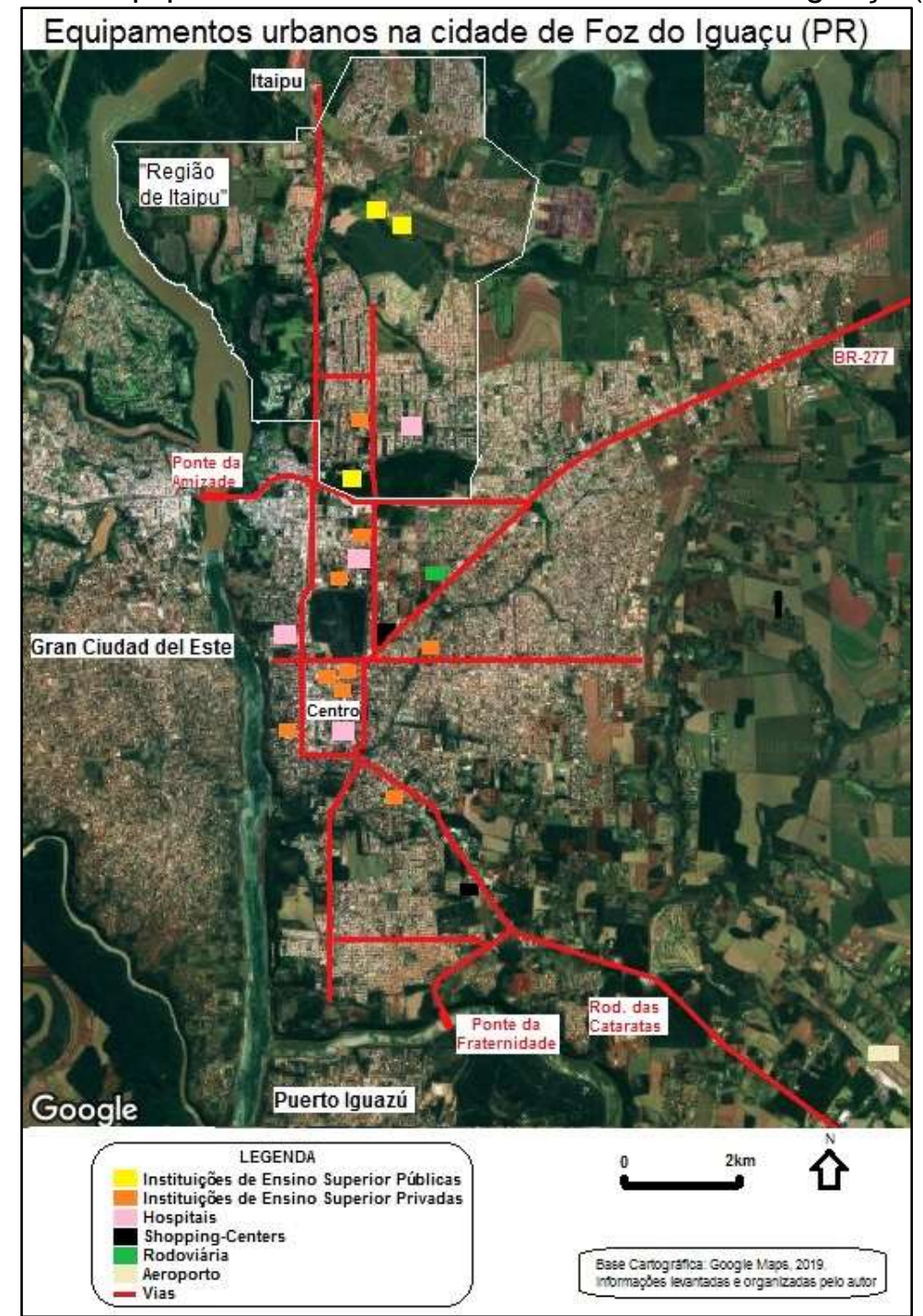

Fonte: Andrade (2019), modificado pelo autor.

Por oferecer uma diversificada estrutura de comércio, órgãos públicos, entretenimento, escolas, faculdades, hospitais e hospedarias, dos mais variados portes e custos, mas também por sua importância histórica e simbólica, o centro de Foz do Iguaçu tem expressiva importância. Para as funções de moradias, mas também comerciais e hoteleiras, esta foi a primeira área da cidade a apresentar expressiva verticalização. Delimitado por importantes vias, em suas cercanias está o Shopping JL Cataratas, fundado em 2007 e o mais antigo do município.

A presença destes equipamentos urbanos colabora para que a área central de Foz do Iguaçu atraia fluxos de pessoas e de veículos de toda a cidade e de outros municípios 
brasileiros, assim como paraguaios e argentinos. Esta área da cidade passa, em especial a partir dos anos 1990, a apresentar significativa verticalização das construções, para fins residenciais e/ou comerciais, mas ao mesmo tempo, mesmo que em menor intensidade que em períodos anteriores, ainda possui ocupações irregulares no seu entorno, majoritariamente nas barrancas do rio Paraná.

As vilas de Itaipu, se anteriormente eram distantes geograficamente e isoladas socialmente, atualmente são parte integrante das dinâmicas econômicas, culturais e socioespaciais que existem na "região de Itaipu", e também na cidade de Foz do Iguaçu e em sua área de influência. E isso se deve à existência de importantes vias (avenidas Paraná e Tancredo Neves, e BR 277), que as interligam com outros pontos do espaço urbano e regional, e, também, pela infraestrutura comercial e de prestação de serviços, com a existência de importantes equipamentos urbanos, como o Hospital Costa Cavalcanti, a Usina de Itaipu e as instituições públicas (UNILA, UNIOESTE, IFPR) e privada (Faculdade Anglo Americano) de ensino superior (figura 3), que atraem pessoas provenientes de outras partes da cidade e da região.

E, após as vendas das moradias, que já não são mais habitadas apenas por pessoas atreladas à usina, a Vila $A$ se consolidou como um subcentro terciário com significativa diversificação funcional, função esta que se iniciou no período de implantação de Itaipu, uma vez que alocou estruturas administrativas, educacionais e de saúde, por sua vez, a Vila B se consolidou como um condomínio residencial fechado de "alto padrão", enquanto a Vila C, historicamente mais periférica, constitui um bairro proletário, mas também atrai estudantes, devido à sua proximidade com os campi universitários. A formação de bairros e loteamentos, que incluem condomínios fechados e ocupações irregulares, foi uma constante na Região de Itaipu, em especial a partir da década de 1990 (Figura 4).

Figura 4: Condomínio Fechado e área favelizada na Região de Itaipu, no ano de 2019

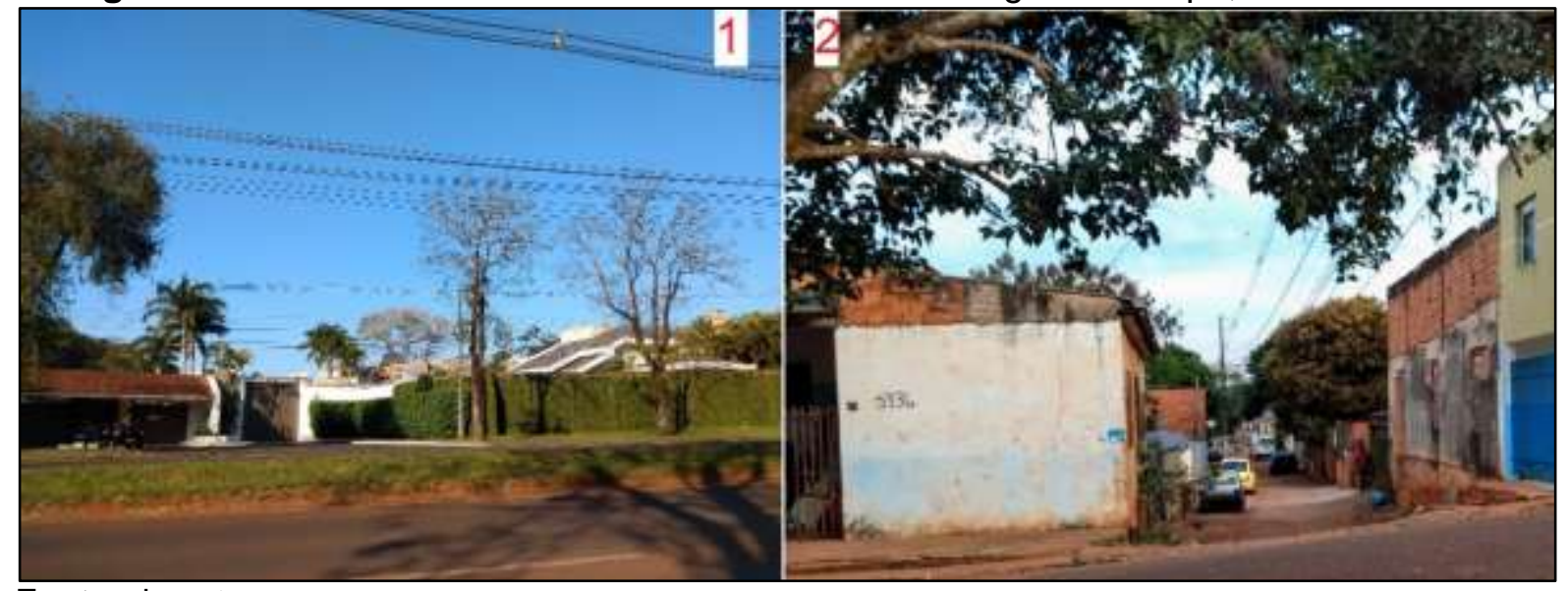

Fonte: do autor. 
Com o processo de expansão urbana, em um município que atravessou constantes altos e baixos com relação aos seus principais ciclos econômicos, Foz do lguaçu apresentou e apresenta significativas desigualdades socioespaciais, que refletem na paisagem urbana e nas vivências cotidianas de seus moradores (Figura 5).

Figura 5: Conjuntos Habitacionais e favelas na cidade de Foz do Iguaçu, em 2019

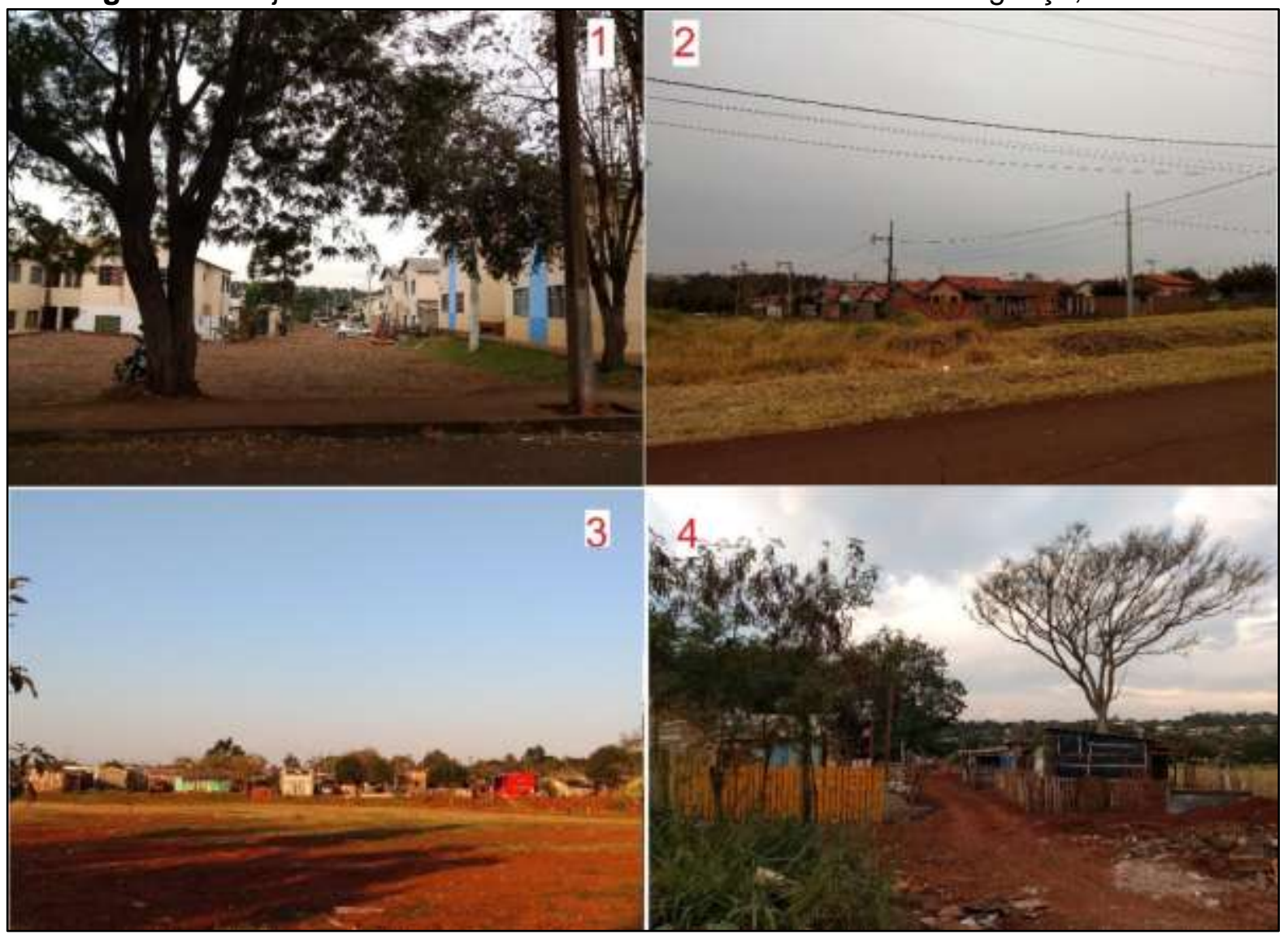

Fonte: do autor.

$\mathrm{Na}$ área central, em que no início dos anos 1990 mais de $12 \%$ das moradias estavam em "aglomerados subnormais" (PREFEITURA MUNICIPAL FOZ DO IGUAÇU, 1995), houve a remoção de habitantes das favelas localizadas próximas ao rio Paraná, tais como Monsenhor e da Marinha, que foram deslocados para a Cidade Nova (foto 2, Figura 5), no extremo norte da cidade, nas imediações da usina de Itaipu, em uma política habitacional, que, dentre outros intuitos, almejava a remoção de favelas do centro (RIBEIRO, 2015). Por sua vez, a favela da Guarda Mirim, nas proximidades da área central, teve significativa parte transformada em blocos de apartamentos (foto 1). Entretanto, nas áreas periféricas da cidade, onde foram implantados os maiores conjuntos residenciais populares, novas favelas se formaram e se consolidaram, como servem de exemplo a do Buba, localizada no Porto Meira (foto 3), assim como o pequeno aglomerado da foto 4, que estava em plena 
implantação das primeiras moradias em julho de 2019, no Bairro das Três Bandeiras (zona leste).

A expansão urbana em direção às áreas periféricas, tais como Três Lagoas, Morumbi, e Porto Meira, se iniciou nos anos 1970 e 1980, no período de maior crescimento da cidade de Foz do Iguaçu, e que ocorreu concomitante à implantação de Itaipu. Apesar de ainda serem consideradas algumas das áreas com maiores precariedades socioeconômicas no município (PREFEITURA MUNICIPAL FOZ DO IGUAÇU, 2016), estes bairros, além de receberem investimentos em políticas de moradias populares, e ao mesmo tempo ocorrerem novas ocupações, como as retratadas na figura 5 , passaram também a alocar importantes subcentros terciários, em especial nas suas principais vias, que fornecem produtos e serviços para seus moradores e de novos bairros das imediações.

Características comuns nas metrópoles, mas também nas cidades médias, em Foz do Iguaçu se desenvolveram diversos subcentros, em especial a partir da década de 1990. Entretanto, a constituição e a distribuição geográfica dos subcentros, em Foz do Iguaçu, refletem duas questões marcantes em suas formações, características e distribuições pelo espaço urbano. Por ter sido uma cidade em que sua expansão se deu de maneira um tanto fragmentada, seja por ações estatais na implantação de Itaipu, mas também pela formação de loteamentos públicos e privados em áreas periféricas, há um significativo número de subcentros, espalhados pelo espaço urbano local (mapa da Figura 6); e, também, apresentam características tanto de "subcentros de bairro", a exemplo dos existentes no Morumbi e nas Três Lagoas (foto 1, figura 6), como também possuem amplas e históricas relações com as cidades dos países vizinhos, a exemplos do Porto Meira em relação a Puerto Iguazú, e especialmente a Vila Portes, onde há comércio de vestuários, alimentos, calçados, e outros artigos voltados especialmente a consumidores provenientes do Paraguai (foto 2, Figura 6).

Com significativa e histórica importância na economia e na organização espacial, a atividade turística também apresenta diversificada apropriação do espaço urbano de Foz do Iguaçu. Os principais atrativos locais, como o Parque Nacional do Iguaçu, a Usina Hidrelétrica de Itaipu, o Marco das Três Fronteiras e as pontes que a interligam com as cidades dos países vizinhos, se encontram em áreas distintas do município, assim como também os templos religiosos, tais como a Mesquita Islâmica e o Templo Budista, que refletem a diversidade sociocultural advinda da imigração internacional. Tal situação faz com que quatro áreas concentrem as estruturas de hospedaria, alimentação e entretenimento.

1 - As vias que partem do centro em direção às Cataratas e a Puerto Iguazú são consideradas como "área turisticamente consolidada" pelos órgãos municipais (RIBEIRO, 2015), devido à presença de hotéis de grande porte, atrativos (Zoo das Aves, Parque Nacional e Complexo Foz do Iguaçu Park Show), centro de convenções e aeroporto, dentre 
outros; nesta área se encontra o subcentro da Vila Yolanda, e no ano de 2016 foi inaugurado o shopping-center Catuaí Palladium (figura 3). 2 - Nas proximidades da Ponte da Amizade, em bairros como Vila Portes e Jardim Jupira, existem pequenos hotéis voltados ao "turismo de compras", e diversos estacionamentos de veículos para as pessoas que atravessam a Ponte da Amizade a pé, seja para o consumo e/ou para as idas e vindas dos migrantes pendulares. 3 - A BR-277, onde estão amplos hotéis, com áreas de lazer, centros de convenções, muito frequentados por grupos de excursões e para a realização de eventos. 4 - A área central, refletindo as diversidades de usos do solo e de suas funcionalidades, assim como a posição geográfica com fácil acesso aos mais diversos atrativos turísticos, com variadas opções de hospedagem, alimentação, consumo e entretenimento.

Figura 6 - Subcentros na cidade de Foz do Iguaçu

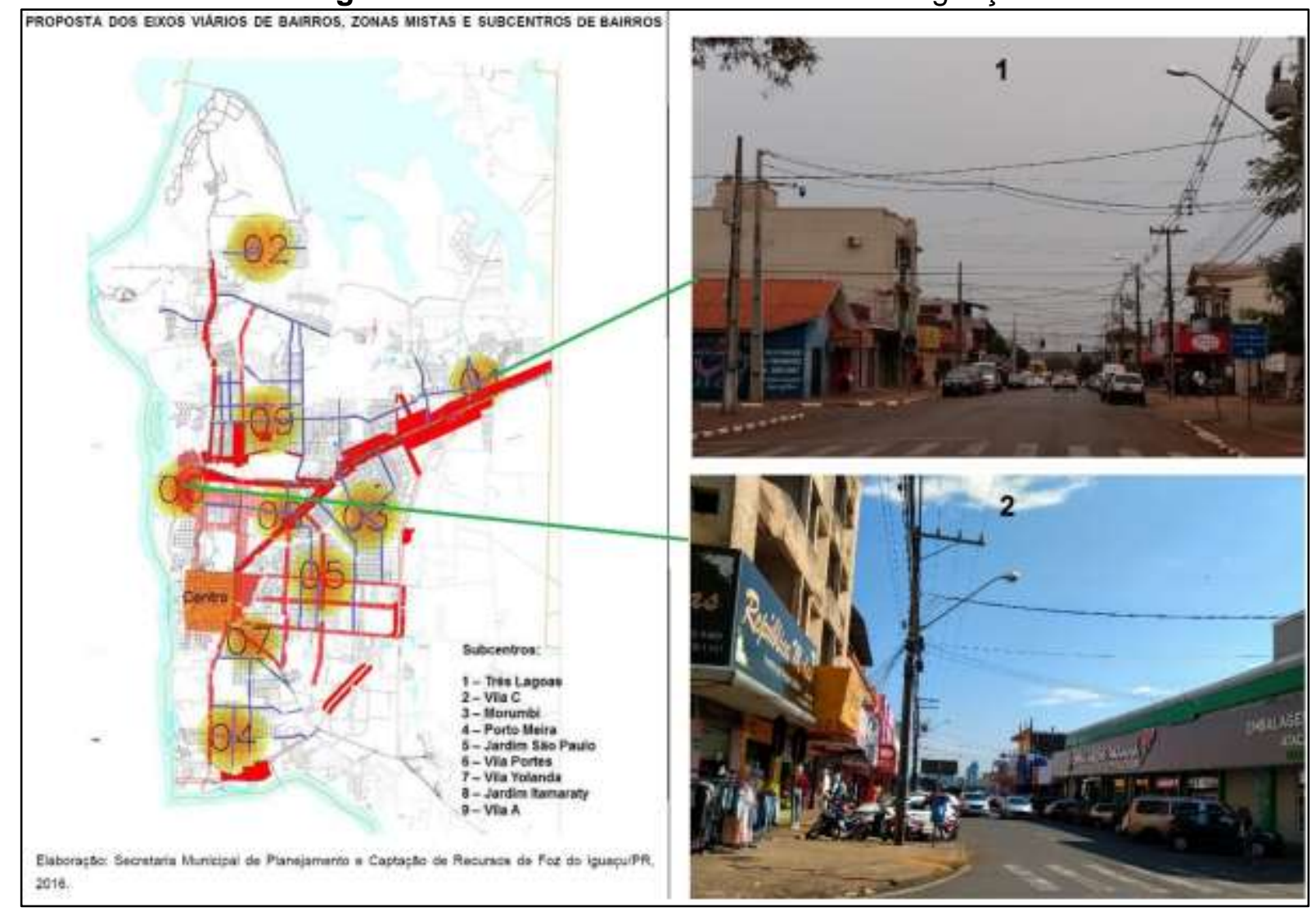

Fontes: mapa - Prefeitura Municipal de Foz do Iguaçu, 2016; fotos: do autor, 2019.

\section{CONSIDERAÇÕES FINAIS}

Como em outras cidades médias brasileiras, o crescimento populacional, a expansão urbana, e as dinâmicas do uso do solo em Foz do Iguaçu resultaram em transformações relevantes, tais como a maior importância na rede urbana regional, a fragmentação do 
espaço urbano, as diferenças socioeconômicas marcantes, e a consolidação de subcentros terciários e de novas centralidades.

Porém é de se salientar três características de Foz do Iguaçu, que são um tanto quanto peculiares se comparadas às diversas cidades médias brasileiras, como o papel de centro receptor de turistas, inclusive internacionais; a existência de uma usina hidrelétrica de grande dimensão, e que demandou dezenas de milhares de trabalhadores em sua construção (Itaipu); e a posição geográfica na fronteira do Brasil com dois países, que formam uma aglomeração urbana com intensa circulação de pessoas, veículos, mercadorias e serviços.

Devido a isso, a cidade de Foz do Iguaçu apresenta significativas diversidades paisagísticas, funcionais e socioculturais, que, aglutinadas ao contexto da Aglomeração Urbana das Três Fronteiras, constitui um espaço marcado pela monumentalidade de suas paisagens (Cataratas e Itaipu), e pelo cosmopolitismo decorrente de uma ampla mistura de povos. Todavia, também se caracteriza pelos amplos contrastes socioeconômicos, que se refletem nas paisagens, nos espaços geográficos e nos cotidianos de seus moradores e visitantes.

\section{REFERÊNCIAS}

ANDRADE, Alexandre Carvalho de. A implantação da Usina Hidrelétrica Itaipu Binacional e as dinâmicas de uma cidade média das Três Fronteiras: o contexto de Foz do lguaçu (PR). In: ALVES, Flamarion Dutra; AZEVEDO, Sandra de C.; COCA, Estevan Leopoldo de Freitas; VALE, Ana Rute do (Org.). A Dimensão política no espaço: conflitos e desigualdades territoriais na sociedade contemporânea. Alfenas: UNIFAL, 2019. pp. 222-243.

BATELLA, Wagner. Cidades médias: da multiplicidade de definições à busca de seus limiares. Caminhos de Geografia, v. 20, n. 20, pp.196-214, 2019.

\section{CARDIN, Eric Gustavo. Sacoleiros e Laranjas na Tríplice Fronteira: uma análise da} precarização do trabalho no capitalismo contemporâneo. Dissertação (Mestrado em Sociologia). UNESP, Araraquara, 2006.

CARDIN, Eric Gustavo. A expansão do capital e as dinâmicas da fronteira. Tese (Doutorado em Sociologia). UNESP, Araraquara, 2010.

CATTA, Luiz Eduardo. O cotidiano de uma fronteira: criminalidade e controle social. Esboços, v. 1, pp. 51-59, 1994.

CATTA, Luiz Eduardo. Fronteira e pobreza: a face da desordem (Foz do lguaçu, 19641992). In: SIMPÓSIO NACIONAL DE HISTÓRIA, XXII. Anais...João Pessoa: ANPUH, 2003. pp. 1-8.

CONTE, Cláudia Heloiza. Compreendendo o papel de Foz do Iguaçu/PR na rede de cidades com base na migração pendular. Terra Plural, v.7, n.1, p. 61-78, 2013.

CORRÊA, Roberto Lobato. Uma nota sobre o urbano e a escala. Território, v.7, n.11-12-13, p. 133-136, 2003.

CORREAA, Roberto Lobato. Construindo o conceito de cidade média. In: SPOSITO, Maria Encarnação Beltrão (org.). Cidades médias: espaços de transição. São Paulo: Expressão Popular, 2007. pp. 23-33. 
CURY, Mauro José Ferreira. Territorialidades Transfronteiriças do Iguassu (TTI): interconexões, interdependências e interpenetrações nas cidades da tríplice fronteira - Foz do Iguaçu (BR), Ciudad del Este (PY) e Puerto Iguazú (AR). Tese (Doutorado em Geografia). UFPR, Curitiba, 2010.

CURY, Mauro José Ferreira; FRAGA, Nilson César. Conurbação transfronteiriça e o turismo na Tríplice Fronteira: Foz do Iguaçu (BR), Ciudad del Este (PY) e Puerto Iguazú (AR). Rosa dos Ventos, 5 (3), p. 460-475, 2013.

DGEEC - Dirección General de Estadística, Encuestas y Censos de Paraguay. Censo Nacional de Poblacíon, 1972.

DGEEC - Dirección General de Estadística, Encuestas y Censos de Paraguay. Censo Nacional de Poblacíon, 1992.

DGEEC - Dirección General de Estadística, Encuestas y Censos de Paraguay. Censo Nacional de Poblacíon, 2012.

DRUCIAKI, Vinicius Polzin. A Usina Hidrelétrica Itaipu Binacional na Tríplice Fronteira BrasilParaguai-Argentina: transformações territoriais e dramas no lugar. SIMPOSIO,

INTERNACIONAL DE LA HISTORIA DE LA ELECTRIFICACIÓN, V... Anais. Évora:

Universidade de Évora, 2019. pp. 88-104.

GASPAR, Lucas Eduardo. As lutas dos trabalhadores por moradia em Foz do Iguaçu, PR (1970-1990). Dissertação (Mestrado em História). UNIOESTE, Marechal Candido Rondon, 2017.

IBGE - Instituto Brasileiro de Geografia e Estatística. Regiões de Influência das Cidades. Rio de Janeiro: IBGE, 2018.

IBGE - Instituto Brasileiro de Geografia e Estatística. Censo Demográfico. Rio de Janeiro: IBGE, 1970.

IBGE - Instituto Brasileiro de Geografia e Estatística. Censo Demográfico. Rio de Janeiro: IBGE, 1991.

IBGE - Instituto Brasileiro de Geografia e Estatística. Censo Demográfico. Rio de Janeiro: IBGE, 2010.

INDEC - Instituto Nacional de Estadística y Censos de la República Argentina. Censo Nacional de Población, Hogares y Viviendas, 1970.

INDEC - Instituto Nacional de Estadística y Censos de la República Argentina. Censo Nacional de Población, Hogares y Viviendas, 1990.

INDEC - Instituto Nacional de Estadística y Censos de la República Argentina. Censo Nacional de Población, Hogares y Viviendas, 2010.

ITAIPU BINACIONAL. La historia de la mayor hidroeléctrica del mundo. Disponível em: https://www.itaipu.gov.py/es/nossahistoria. Acesso em: 07 mar. 2019.

MAZZAROLLO, Juvêncio. A taipa da injustiça. Curitiba: Loyola, 2003.

PREFEITURA MUNICIPAL DE FOZ DO IGUAÇU. Anuário Estatístico. Foz do Iguaçu:

Secretaria Municipal da Coordenação e Planejamento, 1995.

PREFEITURA MUNICIPAL DE FOZ DO IGUAÇU. Plano Diretor de Desenvolvimento Integrado Sustentável. Foz do Iguaçu: Secretaria Municipal de Planejamento, 2016.

PREFEITURA MUNICIPAL DE FOZ DO IGUAÇU. Plano de Mobilidade Urbana de Foz do Iguaçu. Foz do Iguaçu: Parque Tecnológico de Itaipu; Prefeitura Municipal, 2017.

RABOSSI, Fernando. Nas ruas de Ciudad del Este: vidas e vendas num mercado de fronteira. Tese (Doutorado em Antropologia Social). UFRJ, Rio de Janeiro, 2004. 
RAFESTIN, Claude. A ordem e a desordem ou os paradoxos das fronteiras. In: OLIVEIRA, Tito Carlos Machado de (Org.). Território sem limites: estudos sobre fronteiras. Campo Grande: UFMS, 2005. pp. 9-15.

RIBEIRO, Maria de Fátima Bento. Memórias do concreto: vozes na construção de Itaipu. Cascavel: Edunioeste, 2003.

RIBEIRO, Maria de Fátima Bento. Itaipu, a dança das águas: histórias e memórias de 1966 a 1984. Tese (Doutorado em História). UNICAMP, Campinas, 2006.

RIBEIRO, Danilo George. Metamorfoses na cidade: tensões e contradições na produção e apropriação do espaço urbano em Foz do Iguaçu. Dissertação (Mestrado em Ciências Sociais). UNIOESTE, Toledo, 2015.

RIPPEL, Ricardo. Migração e desenvolvimento econômico no Oeste do estado do Paraná: uma análise de 1950 a 2000. Tese (Doutorado em Demografia). UNICAMP, Campinas, 2005.

ROSEIRA, Antônio Marcos. Foz do Iguaçu: cidade rede sul-americana. Dissertação (Mestrado em Geografia Humana). USP, São Paulo, 2006.

SERPA, Ângelo. A paisagem periférica. In: YÁZIGI, Eduardo (Org). Turismo e paisagem. São Paulo: Contexto, 2002. p. 133 - 147.

SOUZA, Adelita Araujo de. Itaipu e a urbanização da zona de fronteira do Iguaçu. Cidades e Conjuntos Habitacionais da Usina Hidrelétrica. Dissertação (Mestrado em Urbanismo). PUC, Campinas, 2011.

SOUZA, Aparecida Darc de. Formação econômica e social de Foz do Iguaçu (PR): um estudo sobre as memórias constitutivas da cidade (1970-2008). Tese (Doutorado em História). PUC, São Paulo, 2009.

SOUZA, Edson Belo Clemente de. A região do Lago de Itaipu: as políticas públicas a partir dos governos militares e a busca da construção de um espaço regional.

Dissertação (Mestrado em Geografia). UFSC, Florianópolis, 1998.

SPOSITO, Maria Encarnação Beltrão. Loteamentos fechados em cidades médias paulistas. In: SPOSITO, Eliseu Savério; SPOSITO, Maria Encarnação Beltrão; SOBARZO, Oscar (Org). Cidades médias: produção do espaço urbano e regional. São Paulo: Expressão Popular, 2006. pp. 175-197.

THAUMATURGO, Leila Regina Youssef. A expansão urbana e o crescimento populacional em áreas do entorno de grandes reservatórios: o caso de Foz do Iguaçu. Tese (Doutorado em Engenharia Mecânica). UNESP, Guaratinguetá, 2011.

YÁZIGI, Eduardo. Civilização urbana, planejamento e turismo. São Paulo: Contexto, 2003.

Recebido: maio de 2021. Aceito: setembro de 2021. 